\title{
Implementasi Metode Klasifikasi Dengan Algoritma Support Vector Machine Untuk Menentukan Stok Persediaan Barang Pada Koperasi Karyawan Pangan Utama
}

\author{
Fadjar Pratama ${ }^{1}$, Muhammad Nasir ${ }^{2}$, Siti Sauda*3 \\ 1,2,3Informatics Departement, Bina Darma University, Palembang, Indonesia \\ Email: fadjarpratama97@gmail.com ${ }^{1}$, nasir@binadarma.ac.id², siti_sauda@binadarma.ac.id ${ }^{3}$
}

\begin{abstract}
Abstrak
Koperasi Karyawan Pangan Utama merupakan koperasi yang disediakan untuk memenuhi kebutuhan karyawan PT. Indofood cabang Palembang pada khususnya dan masyarakat pada umumnya. Koperasi Karyawan Pangan Utama ini melaksanakan berbagai kegiatan usaha antara lain unit usaha pertokoan dan unit usaha simpan pinjam. Penyimpanan data yang digunakan oleh Koperasi Karyawan Pangan Utama dalam proses persediaan barang walaupun sudah terkomputerisasi, namun prosesnya belum terintegrasi dengan baik, sehingga menimbulkan sebuah masalah bagi Koperasi Karyawan Pangan Utama yaitu kesulitan memperoleh informasi mengenai persediaan barangnya dan terkadang sering terjadinya penumpukan barang yang merugikan bagi Koperasi Karyawan Pangan Utama. Dengan menerapkan pengolahan persediaan barang menggunakan algoritma Support Vector Machine yang baik, diharapkan terjadinya interaksi yang baik dalam management stok barang dengan cepat, efisien, dan efektif. Algoritma Support Vector Machine adalah algoritma yang mencatat kenaikan dan penurunan kas persediaan barang. Proses klasifikasi dengan algortima ini akan menghitung stok awal dengan stok akhir dan mengelompokan barang dagang berdasarkan minat konsumen berdasakan hasil penghitungan stok awal dan stok akhir.
\end{abstract}

Kata Kunci: pengendalian, persediaan, Support Vector Machine

\section{PENDAHULUAN}

Teknologi informasi dan komunikasi yang semakin berkembang saat ini memberikan banyak pilihan dan kemudahan bagi dunia bisnis dalam meningkatkan kinerja mereka. Dari banyak manfaat yang bisa diberikan oleh teknologi antara lain adalah proses bisnis yang berjalan secara real time. Salah satu teknologi yang dapat mewujudkan proses bisnis yang maksimal dalam segi pelayanan dan kualitas barang adalah dengan pendayagunaan internet.

This work is licensed under a Creative Commons Attribution 4.0 International License. 
Dengan adanya internet proses bisnis suatu perusahaan dapat dilakukan dengan efektif dan efisien. Pemanfaatan internet didalam perusahaan antara lain seperti pengiriman informasi melalui e-mail, transaksi e-commerce, transaksi e-banking dan proses penentuan stok persediaan barang yang dapat memanfaatkan penggalian data.

Koperasi Karyawan Pangan Utama merupakan koperasi yang disediakan untuk memenuhi kebutuhan karyawan PT. Indofood cabang Palembang pada khususnya dan masyarakat pada umumnya. Koperasi Karyawan Pangan Utama ini melaksanakan berbagai kegiatan usaha antara lain unit usaha pertokoan dan unit usaha simpan pinjam. Dalam proses penyimpanan data untuk persediaan barang, Koperasi Karyawan Pangan Utama hanya menggunakan microsoft excel tanpa proses data mining. Sehingga dapat menimbulkan sebuah masalah bagi Koperasi Karyawan Pangan Utama yaitu kesulitan memperoleh informasi mengenai persediaan barangnya dan terkadang sering terjadinya penumpukan barang yang merugikan bagi Koperasi Karyawan Pangan Utama.

\section{METODOLOGI PENELITIAN}

Pada bagian ini penulis akan menguraikan beberapa hal yang digunakan dalam penulisan penelitian. Hal berikut antara lain adalah 1) Metode penelitian, 2) Metode pengumpulan data dan 3) Metode pengembangan sistem.

\subsection{Metode Penelitian}

Metode penelitian yang digunakan adalah metode deskriptif (Deskriptive Research). [1] Metode penelitian deskriptif adalah metode yang digunakan untuk menggambarkan atau menganalisa suatu hasil penelitian tetapi tidak digunakan untuk membuat kesimpulan yang lebih luas.

\subsection{Metode Pengumpulan Data}

Metode pengumpulan data yang dilakukan dalam penelitian [2] yaitu:

1) Pengamatan (Observasi), Merupakan metode pengumpulan data dengan cara berkunjung secara langsung ke Koperasi Karyawan Pangan Utama dengan melakukan pengamatan langsung tempat dan proses persediaan stok barang. 
2) Wawancara (Interview), Merupakan metode pengumpulan data dengan cara proses tanya jawab seputar persediaan stok barang kepada pegawai dan pemilik, dengan tujuan untuk mendapatkan gambaran tentang stok barang serta masalah yang berhubungan dengan penelitian.

3) Studi Pustaka, Merupakan proses pengumpulan data dengan cara mencari dan mempelajari data-data dari buku-buku ataupun dari referensi lain yang berhubungan dengan penulisan skripsi ini.

\subsection{Metode Pengembangan Sistem}

Metode pengembangan sistem yang digunakan untuk membangun ecooperative pada Koperasi Karyawan Pangan Utama, penulis menggunakan Metode Prototype, metode ini merupakan salah satu metode yang banyak digunakan dalam pengembangan perangkat lunak [3].Berikut ini penjelesan mengenai tahapan pada metode pengembangan yang digunakan, yaitu:

1) Komunikasi, Tahapan awal dari model prototype guna mengidentifikasi permasalahan-permasalahan yang ada, serta informasi-informasi lain yang diperlukan untuk pengembangan sistem.

2) Perencanaan, Tahapan ini dikerjakan dengan kegiatan penentuan sumber daya,

3) spesifikasi untuk pengembangan berdasarkan kebutuhan sistem, dan tujuan berdasarkan pada hasil komunikasi yang dilakukan agar pengembangan dapat sesuai dengan yang diharapkan review"

4) Pemodelan, Tahapan selanjutnya ialah representasi atau menggambarkan model sistem yang akan dikembangkan seperti proses dengan perancangan menggunakan UML, relasi antarentitas yang diperlukan, dan perancangan antarmuka dari sistem yang akan dikembangkan.

5) Konstruksi, Tahapan ini digunakan untuk membangun, mengujicoba sistem yang dikembangkan. Proses instalasi dan penyediaan user-support juga dilakukan agar sistem dapat berjalan dengan sesuai.

6) Penyerahan, Tahapan ini dibutuhkan untuk mendapatkan feedback dari pengguna, sebagai hasil evaluasi dari tahapan sebelumnya dan implementasi dari sistem yang dikembangkan. 


\section{Journal of Software Engineering Ampera}

Vol. 1, No. 2, June 2020 e-ISSN: 2775-2488

https://journal-computing.org/index.php/journal-sea/index

\subsection{Klasifikasi}

Klasifikasi merupakan kata serapan dari bahasa Belanda, classificatie, yang sendirinya berasal dari bahasa Prancis classification. Istilah ini menunjuk kepada sebuah metode untuk menyusun data secara sistematis atau menurut beberapa aturan atau kaidah yang telah ditetapkan. Klasifikasi adalah pengelompokkan yang sistematis pada sejumlah objek,gagasan, buku atau benda-benda lain ke dalam kelas atau golongan tertentuberdasarkan ciri-ciri yang sama [4].

\subsection{Support Vector Machine}

Support Vector Machine (SVM) adalah suatu teknik untuk melakukan prediksi, baik dalam kasus klasifikasi maupun regresi. SVM memiliki prinsip dasar linier classifier yaitu kasus klasifikasi yang secara linier dapat dipisahkan, namun SVM telah dikembangkan agar dapat bekerja pada problem non-linier dengan memasukkan konsep kernel pada ruang kerja berdimensi tinggi. Pada ruang berdimensi tinggi, akan dicari hyperplane yang dapat memaksimalkan jarak (margin) antara kelas data.Algoritma Support Vector Machine (SVM) merupakan salah satu teknik untuk melakukan prediksi, baik dalam kasus klasifikasi maupun regresi.

\section{HASIL DAN PEMBAHASAN}

Berdasarkan dari analisis - analisis dan rancangan yang telah dijelaskan sebelumnya maka dibangunlah sebuah sistem pengolahan data stok barang meggunakan metode Klasifikasi. Sistem ini berperan sebagai sebuah sistem untuk mengolah data stok barang pada koperasi karyawan pangan utama agar dapat membantu koperasi karyawan dalam hal mengatur persediaan barang. Berikut ini adalah gambaran dari aplikasi yang telah dibagun dan rancangan 1) Use case diagram, 2) Class Diagram. Komponen utama dari aplikasi tersebut terdiri dari beberapa menu - menu, yaitu 3) Menu login 4) Menu utama 5) Menu bobot, 6) Menu nilai dan 7) Menu tentang aplikasi.

\section{1) Use Case Diagram}

Diagram use case digunakan untuk memperlihatkan hubungan-hubungan yang terjadi antara aktor-aktor dengan use case-use case yang ada dalam Implementasi Metode Klasifikasi dengan Algoritma Support Vector Machine untuk Menentukan Stok Persediaan Barang pada Koperasi Karyawan Pangan 


\section{Journal of Software Engineering Ampera}

Vol. 1, No. 2, June 2020 e-ISSN: 2775-2488

https://journal-computing.org/index.php/journal-sea/index

Utama, sehingga calon pengguna sistem/perangkat lunak mendapatkan pemahaman tentang sistem yang akan dikembangkan.

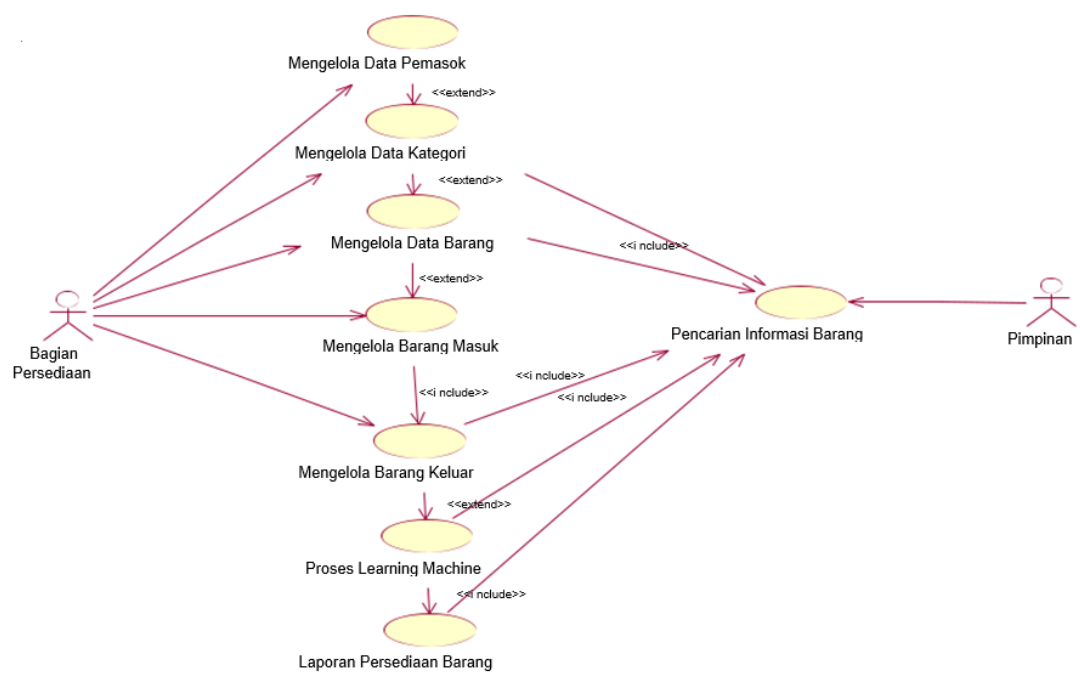

Gambar 1 Usecase Diagram

\section{2) Class Diagram}

Mengidentifikasi isi informasi yang akan ditampilkan pada Implementasi Metode Klasifikasi dengan Algoritma Support Vector Machine untuk Menentukan Stok Persediaan Barang pada Koperasi Karyawan Pangan Utama. Adapun isi informasi yang akan di tampilkan tersebut di deskripsikan melalui Class Diagram sebagai berikut ini.

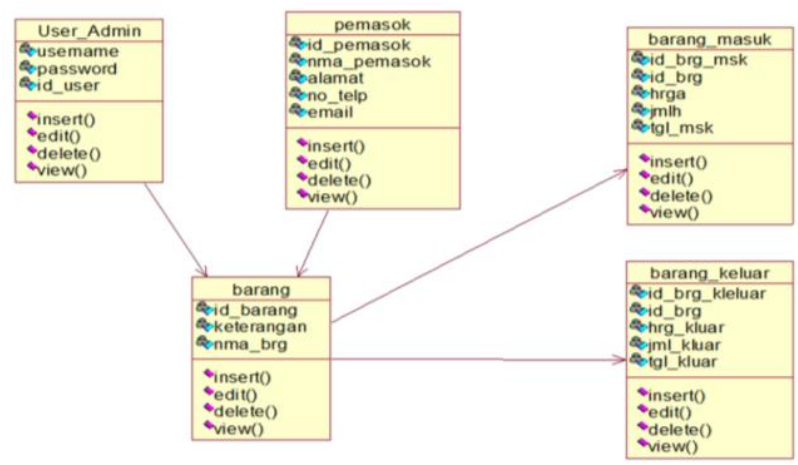

Gambar 2. Class Diagram 


\section{Journal of Software Engineering Ampera}

Vol. 1, No. 2, June 2020 e-ISSN: 2775-2488

https://journal-computing.org/index.php/journal-sea/index

\section{3) Halaman Login}

Halaman Login akan ditampilkan setelah membuka aplikasi menggunakan browser.

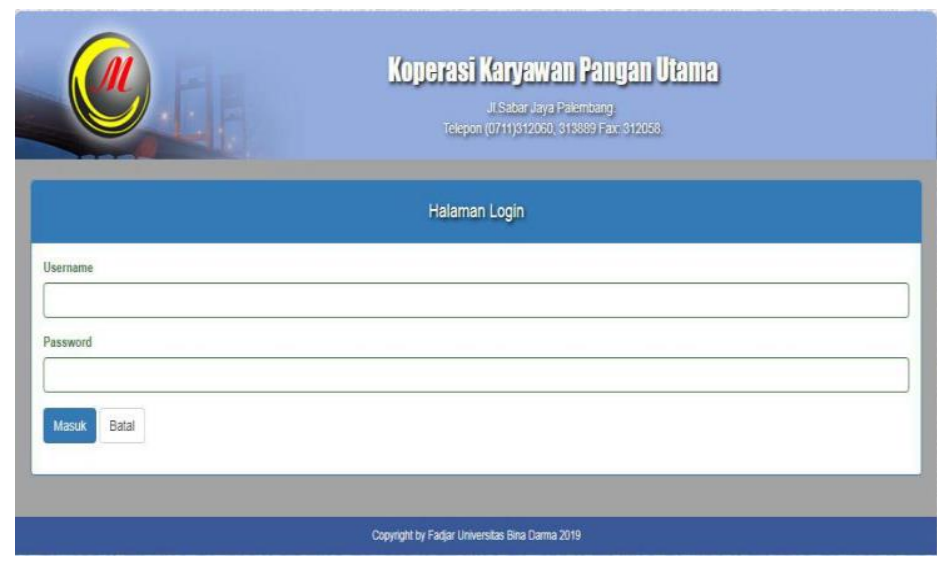

Gambar 3 Halaman Login

\section{4) Halaman Bagian Persediaan}

Halaman Bagian Persediaan akan ditampilkan setelah Admin berhasil melakukan login mengggunakan username dan password di browser.

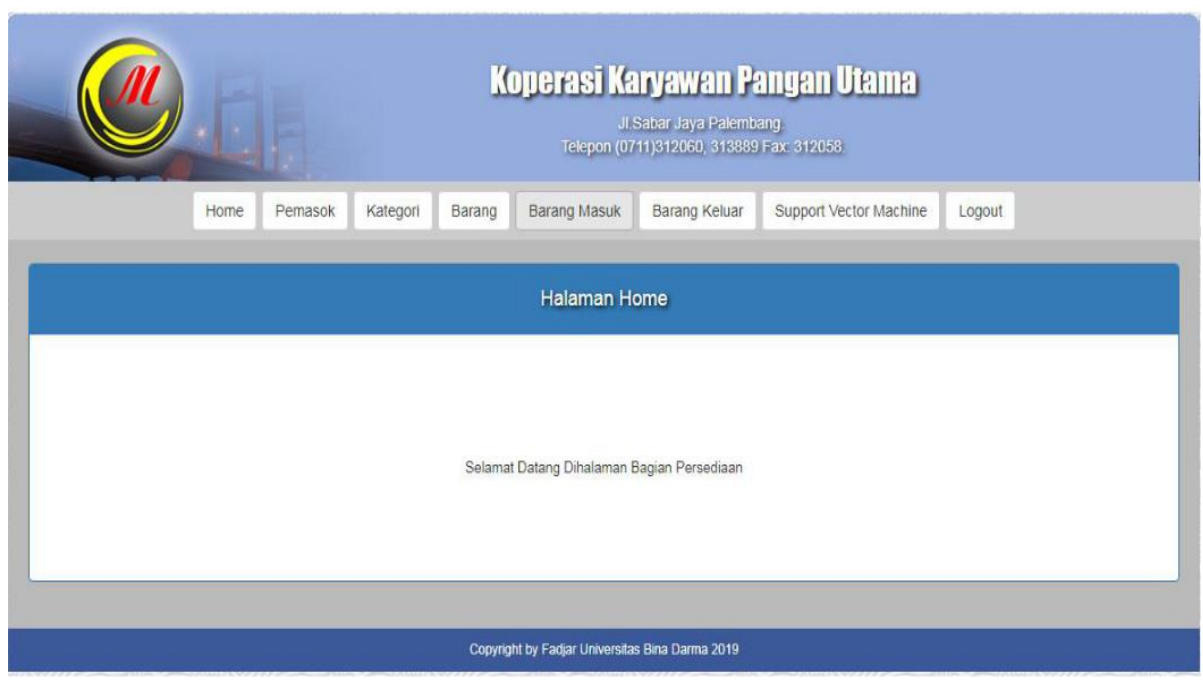

Gambar 4 Halaman Bagian Persediaan 


\section{Journal of Software Engineering Ampera}

Vol. 1, No. 2, June 2020 e-ISSN: 2775-2488

https://journal-computing.org/index.php/journal-sea/index

\section{5) Halaman Barang}

Halaman Barang akan ditampilkan setelah Admin memilih menu Barang, yang digunakan untuk mengelola data barang.

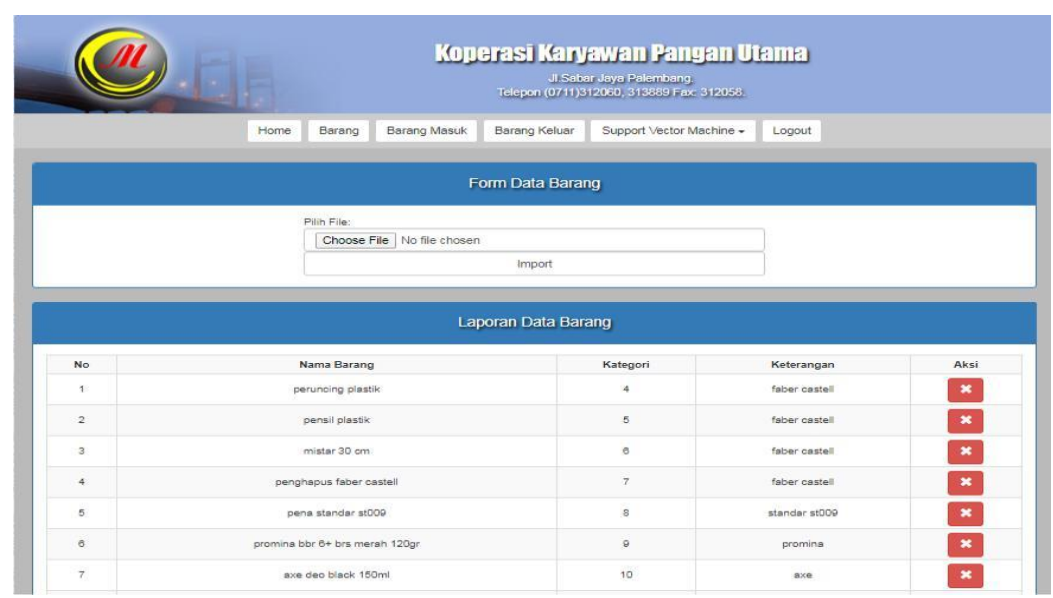

Gambar 5. Halaman Barang

\section{6) Halaman Barang Masuk}

Halaman Barang Masuk akan ditampilkan setelah Admin memilih menu Barang Masuk, yang digunakan untuk mengelola data barang masuk.

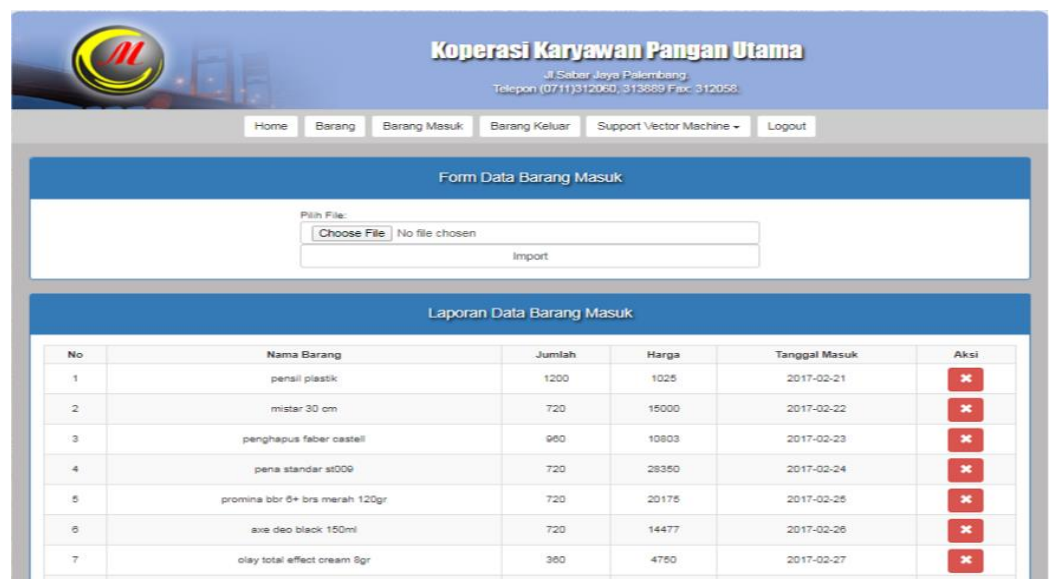

Gambar 6. Halaman Barang Masuk 


\section{Journal of Software Engineering Ampera}

Vol. 1, No. 2, June 2020 e-ISSN: 2775-2488

https://journal-computing.org/index.php/journal-sea/index

\section{7) Halaman Barang Keluar}

Halaman Barang Keluar akan ditampilkan setelah Admin memilih menu Barang Keluar, yang digunakan untuk mengelola data barang keluar.

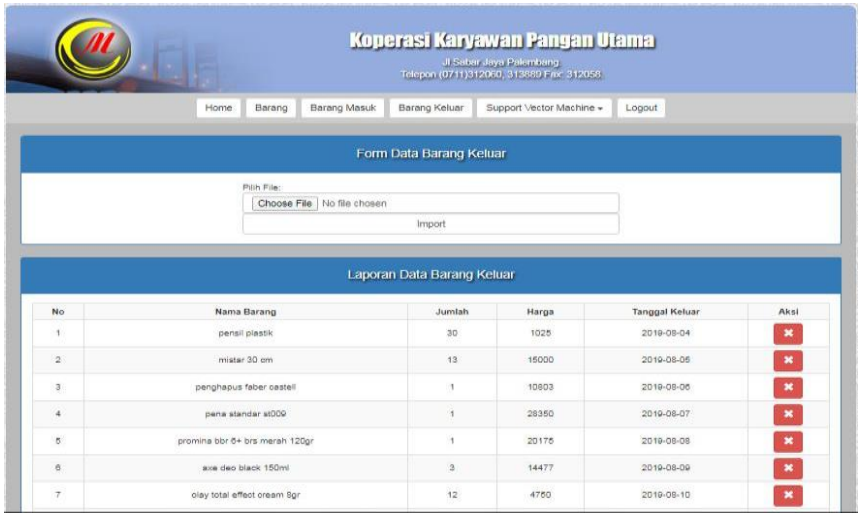

Gambar 7. Halaman Barang Keluar

\section{8) Transformasi Data}

Seperti terlihat pada gambar 8 terlihat bahwa transformasi data terdiri dari nilai $X 1$ dan $X 2$. Untuk $X 1$ dan $X 2$ diambil dari data yang telah ditransformasikan yaitu urutan nilai dengan cara menghitung jumlah barang pada data pertama dikurang jumlah barang terendah lalu dibagi jumlah data tertinggi dikurang jumlah data terendah yang mana menghasilkan transformasi data untuk $X 1$ adalah $=0.1027,0.1025,0.1024,0.1032,0.1027$. untuk $X 2$ adalah $=0.1112,0.1091,0.109,0.1105,0.1096,0.109$.

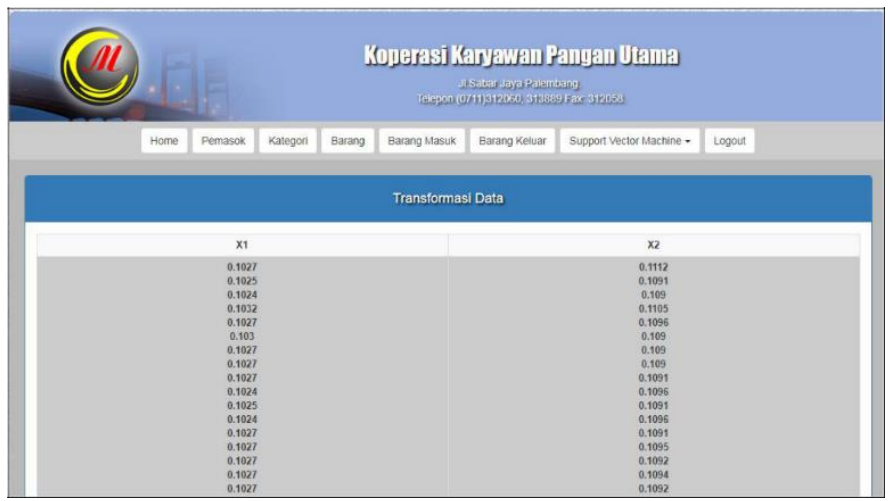

Gambar 8 Hasil Perhitungan Transformasi Data 


\section{Journal of Software Engineering Ampera}

Vol. 1, No. 2, June 2020 e-ISSN: 2775-2488

https://journal-computing.org/index.php/journal-sea/index

\section{9) Data Latih}

Untuk hasil perhitungan data latih $X 2-X 1$ dan $L A B E L$ dimana menunjukan hasil prediksi sementara adalah negatif maka label data latih $(-1)$ yang menunjukan hasil klasifikasi tidak laris, sedangkan hasil prediksi sementara positif maka label data latih $(+1)$ yang menunjukan hasil klasifikasi laris.

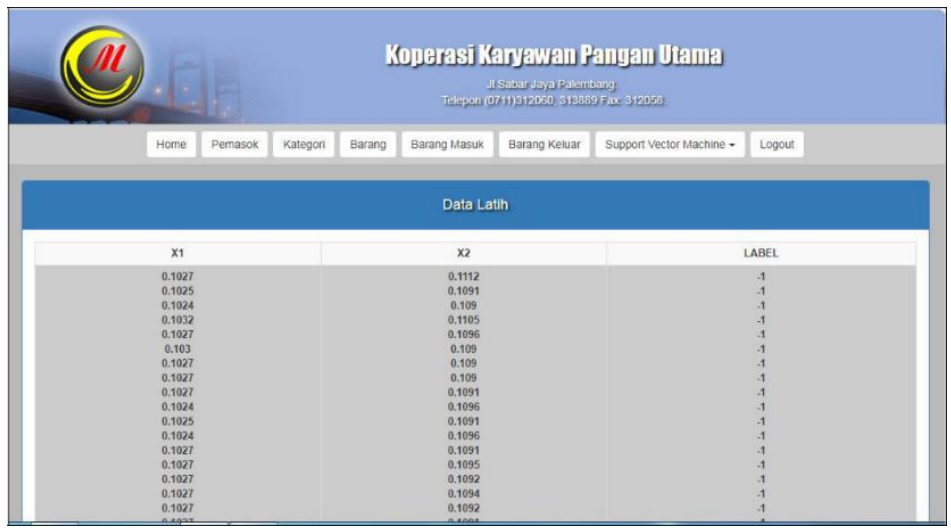

Gambar 9. Hasil Perhitungan Data Latih

\section{0) Data Uji}

Untuk hasil perhitungan data uji $X 2-X 1$ dan $L A B E L$ dimana menunjukan hasil prediksi sementara adalah negatif maka label data uji (-1) yang menunjukan hasil klasifikasi tidak laris, sedangkan hasil prediksi sementara positif maka label data latih $(+1)$ yang menunjukan hasil klasifikasi laris. Dominan bernilai $(+1)$ yakni klasifikasi laris.

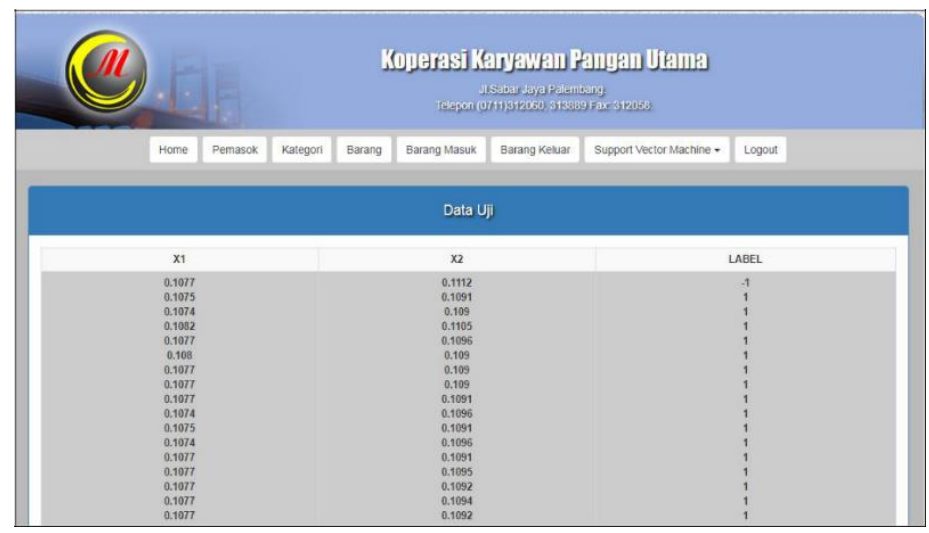

Gambar 11 Hasil Perhitungan Data Uji 


\section{Journal of Software Engineering Ampera}

Vol. 1, No. 2, June 2020 e-ISSN: 2775-2488

https://journal-computing.org/index.php/journal-sea/index

\section{1) Hasil Prediksi}

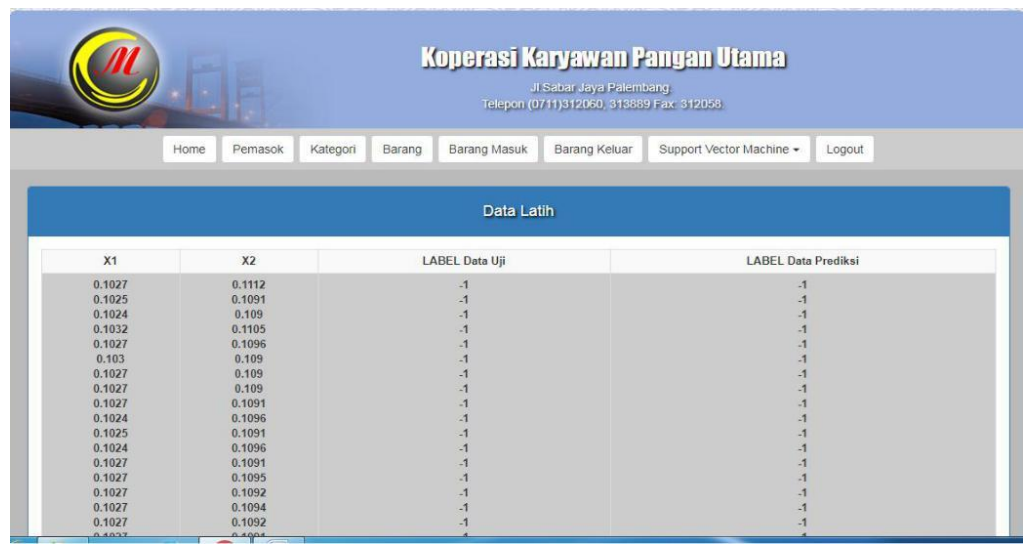

Gambar 12 Hasil Perhitungan Hasil Prediksi

Berdasarkan hasil perhitungan tingkat akurasi data uji yang diolah secara manual menggunakan metode Support Vector Machine dengan kernel nilai label data uji dan label data prediksi.

\section{2) Support Vector Machine}

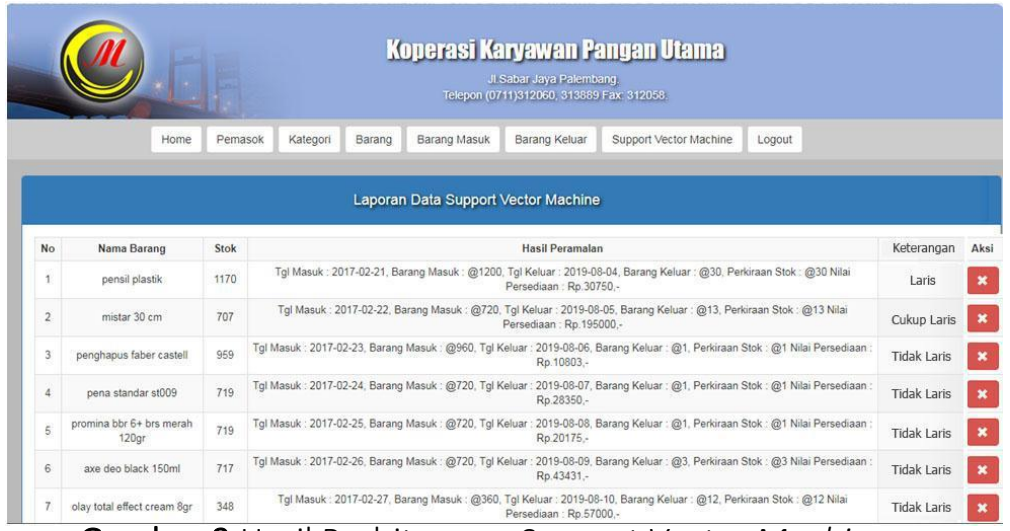

Gambar 9 Hasil Perhitungan Support Vector Machine

Gambar diatas menjelaskan mengenai produk tabel laporan data Support Vector Machine, yang terdiri dari menu no, nama barang, stok, hasil peramalan, keterangan dan aksi, dimana pada kolom aksi menampilkan keterangan laris, cukup laris dan tidak laris. 


\section{Journal of Software Engineering Ampera}

Vol. 1, No. 2, June 2020 e-ISSN: 2775-2488

https://journal-computing.org/index.php/journal-sea/index

\section{KESIMPULAN}

Berdasarkan hasil penelitian penulis yang berjudul "Implementasi Metode Klasifikasi dengan Algoritma Support Vector Machine untuk Menentukan Stok Persediaan Barang pada Koperasi Karyawan Pangan Utama" serta pembahasan yang dilakukan oleh penulis maka dapat diambil kesimpulan bahwa:

1) Implementasi Metode Klasifikasi dengan Algoritma Support Vector Machine untuk Menentukan Stok Persediaan Barang pada Koperasi Karyawan Pangan Utama yang dibuat telah melalui tahapan yang terdiri dari tahapan analisis dan tahapan desain dengan menggunakan metode pengembangan prototype.

2) Bahasa pemrograman PHP dipilih karena alasan kompatibilitas, yaitu menyesuaikan dengan aplikasi lain yang telah lebih dahulu beroperasi.

3) Sarana informasi persediaan, barang masuk, barang keluar mudah dilakukan untuk jangkauan yang luas.

4) Dengan adanya Implementasi Metode Klasifikasi dengan Algoritma Support Vector Machine untuk Menentukan Stok Persediaan Barang pada Koperasi Karyawan Pangan Utama diharapkan mampu memudahkan proses pelayanan pelanggan.

\section{DAFTAR PUSTAKA}

[1] Sugiyono. 2005. "Metode Penelitian Administrasi". Bandung: Alfabeta.

[2] Supardi. 2005. "Metodologi Penelitian Ekonomi dan Bisnis". Yogyakarta:UII Press

[3] Asrningtias, Y \& Mardhiyah, R. 2014. Áplikasi Data Mining Untuk Menampilkan Informasi Tingkat Kelulusan Mahasiswa". Jurnal Informatika, 8 (1):1-12.

[4] Hamakonda, Towa P. dan J.N.B. Tairas. 1995. "Pengantar Klasifikasi Persepuluhan Dewey". Jakarta: Gunung Mulia

[5] Octavian,dkk. 2014. "Penerapan Metode Support Vector Machine Pada Data Akreditasi Sekolah Dasar Di Kabupaten Malang". Jurnal Gaussian, 3 (4):811-820. 